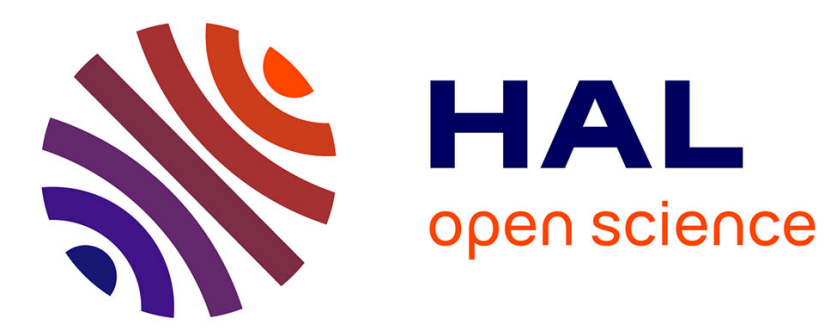

\title{
Fault-tolerant semi-active suspension control for degradation in damper performance
}

\author{
Hakan Basargan, András Mihály, Péter Gáspár, Olivier Sename
}

\section{To cite this version:}

Hakan Basargan, András Mihály, Péter Gáspár, Olivier Sename. Fault-tolerant semi-active suspension control for degradation in damper performance. MED 2021 - 29th Mediterranean Conference on Control and Automation, Jun 2021, Bari (virtual), Italy. 10.1109/MED51440.2021.9480288 . hal03301881

\section{HAL Id: hal-03301881 \\ https://hal.univ-grenoble-alpes.fr/hal-03301881}

Submitted on 27 Jul 2021

HAL is a multi-disciplinary open access archive for the deposit and dissemination of scientific research documents, whether they are published or not. The documents may come from teaching and research institutions in France or abroad, or from public or private research centers.
L'archive ouverte pluridisciplinaire HAL, est destinée au dépôt et à la diffusion de documents scientifiques de niveau recherche, publiés ou non, émanant des établissements d'enseignement et de recherche français ou étrangers, des laboratoires publics ou privés. 


\title{
Fault-tolerant semi-active suspension control for degradation in damper performance
}

\author{
Hakan Basargan, András Mihály, Péter Gáspár and Olivier Sename
}

\begin{abstract}
Several types of dampers are used in the suspension systems of road vehicles, while the magneto-rheological damper is one of the most efficient solutions to manage the balance between objectives of vehicle suspension control. Various types of failures may occur in magneto-rheological dampers, and these faults may affect adversely the operation of the vehicle suspension system. This paper is concerned with the design of semi-active suspension control with fault-tolerant control reconfiguration through the Linear Parameter-Varying control method. In case of a damper oil leakage affecting the damper force, the proposed control strategy calculates feasible damper forces for the healthy dampers in order to compensate for the lost force of the faulty damper. Unlike other approaches in the literature, this method aims to enhance performances by modifying the force of a healthy damper to the same level as the force of a faulty damper. The simulation has been performed in the TruckSim environment to demonstrate the operation of the proposed fault-tolerant control strategy. The results show that the introduced novel reconfiguration control method improved driving comfort, road holding and vehicle stability.
\end{abstract}

\section{INTRODUCTION}

The vehicle suspension system consists of three main elements which are damping system, set of mechanical parts and elastic structure. It supports the weight of the vehicle on its wheels and axles, reduces the load from the road, allows the vehicle to move softly over the road irregularities, and enables the vehicle to corner with minimum roll and loss of traction between road and tires. The dampers have significant importance in the vehicle suspension system and characterized by the operating factors, dimension data, and force characteristics [1]. The vehicle dampers are classified

H. Basargan is with Department of Control for Transportation and Vehicle Systems, Budapest University of Technology and Economics, Stoczek u. 2, H-1111 Budapest, Hungary. E-mail: hakan.basargan@kjk. bme. hu

A. Mihály and P. Gáspár are with Systems and Control Laboratory, Institute for Computer Science and Control (SZTAKI), Eötvös Loránd Research Network (ELKH) H-1111, Kende u. 13-17, Budapest, Hungary. E-ma il : [andras.mihaly; peter.gaspar] dsztaki.hu

O. Sename is with GIPSA-lab, INPG, Université Grenoble Alpes, 11 Rue des Mathématiques, 38402 Grenoble, France. E-mail: E-mail : olivier.senamedgipsa-lab.grenoble-inp.fr

The research presented in this paper, carried out by Institute for Computer Science and Control was supported by the Ministry for Innovation and Technology and the National Research, Development and Innovation Office within the framework of the National Lab for Autonomous Systems. This paper was partially supported by the National Research, Development and Innovation Office through the project 'Integration of velocity and suspension control to enhance automated driving comfort in road vehicles' (NKFIH 2018-2.1.13-TÉT-FR). The research was partially supported by the Hungarian Government and cofinanced by the European Social Fund through the project "Talent management in autonomous vehicle control technologies" (EFOP-3.6.3-VEKOP- 16-2017-00001). as active, passive, and semi-active according to the capability to adjust the force characteristics. Passive dampers are only able to dissipate the energy, while the active damper is able to dissipate, store, and generate energy. The active dampers are expensive for mass production applications due to their external power supply requirement. Thus, semi-active dampers represent a good solution for controlling the vertical vehicle dynamics using lower cost and energy consumption.

There are several damper types such as monotube, twin-tube, internal-bypass, magneto-rheological(MR), spoolvalve, and electronically controlled. The MR damper is one of the most efficient solutions for managing the balance between the objectives of the vehicle suspension control, which are comfort, road holding, and driving safety. Thus, the MR damper model is considered in this study. The MR damper is a hydraulic device, which has oil in it and this oil contains metallic micro-sized particles that change the rheological properties of the MR fluid when a magnetic field is applied. The smart material of this damper present changeable and functional properties and can be embedded in a damper actuator. The manipulation of the magnetic field is generated by applying an electric current through the damper coil. The damping ratio is modified by the variation of the oil viscosity [2].

Multiple failures may occur for the MR dampers, while these faults may affect adversely the operation of the suspension system. The most common damper fault is oil leakage. The loss of oil by vaporization is for the wear of damper under extreme operations. The oil leakage is generated due to the damaged seals in the damper cover because of high temperature or wear.

Several studies have been presented in fault-tolerant semiactive suspension control, while many of them consider oil leakage problem. The study [3] introduces the design of a fault-tolerant semi-active suspension controller, while the fault-tolerant properties of the controller are realized by a Linear Parameter-Varying(LPV) anti-windup approach using saturation indicator scheduling parameters. Its damper force reconfiguration purposes at maximization of ride comfort performance in the damper failures. The studies [4], [5] have also used the LPV approach for their fault-tolerant controller. Du and others [6] investigated the fault diagnosis and fault-tolerant methods of semi-active vehicle suspension system with MR damper to deal with the fault of MR damper. They employed an unknown input observer with robustness and simple structure to detect the fault of the 
MR damper and then designed the skyhook fault-tolerant controller for compensating the system with fault application. The paper [7] introduces state-feedback fault-tolerant control with four modular fault estimation observers, while they discussed seven approaches, analyzed and compared through realistic simulations to show the operation of the approaches. Sergio and Carlos[8] have used a neural network-based approach and their fault isolation module is based on residual generation algorithms.

The present paper proposes a fault-tolerant semi-active suspension control strategy with the LPV control method for the case when one of the dampers suffers from oil leakage. This control strategy calculates feasible damper forces for healthy dampers in order to compensate for the lost force of the faulty damper. This compensation has been realized by changing the level of the other healthy dampers to the same amount as the faulty one. The operation of the proposed strategy is demonstrated in the TruckSim simulation environment. The simulation results show that the proposed fault-tolerant semi-active suspension control strategy improves vehicle comfort and stability.

The paper is organized as follows: Section II presents the control-oriented quarter-car model and the LPV controller synthesis of the semi-active suspension. Section III introduces the fault-tolerant reconfiguration method. Section IV demonstrates the operation of the introduced method in highfidelity TruckSim simulation environment, while concluding remarks are presented in Section V.

\section{SEMI-ACTIVE SUSPENSION CONTROL}

This section consists of modeling of the quarter-car model and control design of the semi-active suspension control.

Numerous studies have already been introduced related to semi-active suspension control topic with different control methods. These methods such as linear-quadratic (LQ), $\mathcal{H}_{2}$ and $\mathcal{H}_{\infty}$ suspension control guarantee good performance in driving comfort and vehicle stability, while due to their fixed weighting of performance property, a dynamic control reconfiguration is not possible. Therewith, the LPV framework is a good solution for the dynamic control reconfiguration. In this study, the semi-active suspension control is founded on the LPV framework, as already introduced in previous studies [9], [10], [11].

The two-degree-of-freedom quarter-car model shown in Figure 1 is used in this study. The quarter-car semi-active suspension system and the actuator's dynamic model is written as Equation (1).

$$
\begin{array}{r}
m_{s} \ddot{q}_{1}+b_{s}\left(\dot{q}_{1}-\dot{q}_{2}\right)+k_{s}\left(q_{1}-q_{2}\right)+F_{m r}=0 \\
\text { (1a) } \\
m_{u} \ddot{q}_{2}+b_{s}\left(\dot{q_{2}}-\dot{q}_{1}\right)+k_{t}\left(q_{2}-w\right)+k_{s}\left(q_{2}-q_{1}\right)-F_{m r}=0
\end{array}
$$

The actuator dynamics is approximated as Equation (2).

$$
\dot{F}_{m r}=-\frac{1}{\tau} F_{m r}+\frac{1}{\tau} u
$$

where, $m_{s}$ and $m_{u}$ are the sprung and unsprung mass of the quarter vehicle, $k_{t}$ and $k_{s}$ are the stiffness of the tire and spring, $b_{s}$ is the damping rate of the shock absorber, $F_{m r}$ is the control force generated by the actuator and $u$ is the control input of the system. Note, that $q_{1}$ and $q_{2}$ are the vertical displacement of the sprung mass and the unsprung mass, while road disturbance is expressed with $w$. The parameters of the quarter-car model for the rear and front suspension is shown in Table I.

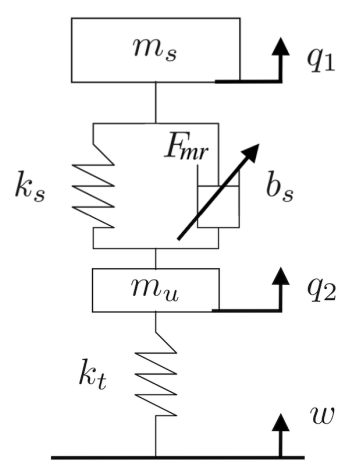

Fig. 1. Quarter-car model

TABLE I

SUSPENSION PARAMETERS

\begin{tabular}{|l|l|l|l|}
\hline $\begin{array}{l}\text { Parameters } \\
\text { (symbols) }\end{array}$ & $\begin{array}{l}\text { Front } \\
\text { suspension }\end{array}$ & $\begin{array}{l}\text { Rear } \\
\text { suspension }\end{array}$ & Unit \\
\hline \hline sprung mass $\left(m_{s}\right)$ & 214 & 336 & $\mathrm{~kg}$ \\
unsprung mass $\left(m_{u}\right)$ & 40 & 40 & $\mathrm{~kg}$ \\
suspension stiffness $\left(k_{s}\right)$ & 30 & 60 & $\mathrm{kN} / \mathrm{m}$ \\
tire stiffness $\left(k_{t}\right)$ & 220 & 220 & $\mathrm{kN} / \mathrm{m}$ \\
damping $\left(b_{s}\right)$ & 50 & 50 & $\mathrm{~N} / \mathrm{m} / \mathrm{s}$ \\
time constant $(\tau)$ & $1 / 30$ & $1 / 30$ & $\mathrm{~s}$ \\
\hline
\end{tabular}

The unmodelled dynamics $\Delta$ are considered with $\left|\Delta\left(\omega_{1}\right)\right|=0.25$ at low frequencies and $\left|\Delta\left(\omega_{2}\right)\right|=1$ at high frequencies, and is assumed that it is stable with the norm condition $\|\Delta\|_{\infty}<1$. The state vector is $x=$ $\left[\begin{array}{lllll}x_{1} & x_{2} & x_{3} & x_{4} & x_{5}\end{array}\right]^{T}$, in which the components are $x_{1}=q_{1}, x_{2}=q_{2}, x_{3}=\dot{q}_{1}, q_{4}=\dot{q}_{2}$ and $x_{5}=F_{m r}$.

The performance specifications are defined as:

- In order to increase passenger comfort, the acceleration of the sprung mass must be minimized with the following optimization criterion: $z_{1}=\ddot{q}_{1} \rightarrow 0$.

- In order to ensure stability of the vehicle, the minimization of suspension deflection is required with $z_{2}=$ $\left(q_{1}-q_{2}\right) \rightarrow 0$.

- The tire load must also be minimized to reduce side forces in order to guarantee stability: $z_{3}=\left(q_{2}-w\right) \rightarrow$ 0 .

- The control force is considered to avoid actuator saturation: $z_{4}=F_{m r} \rightarrow 0$.

The performance vector $z=\left[\begin{array}{llll}z_{1} & z_{2} & z_{3} & z_{4}\end{array}\right]^{T}$ is defined with performance specifications. In the design, the 
measured signal is chosen as relative displacement between the masses, i.e $y=x_{1}-x_{2}$. The control input $u$ is the vertical force generated by the MR damper with Equation (2).

The system given with (1) is transformed into state space representation form as below:

$$
\begin{aligned}
\dot{x} & =A x+B_{1} w+B_{2} u \\
z & =C_{1} x+D_{11} w+D_{12} u \\
y & =C_{2} x+D_{21} w+D_{22} u
\end{aligned}
$$

The matrices can be found in the previous work of authors[10]. The introduced controller is founded on a closed-loop architecture shown in Figure 2.

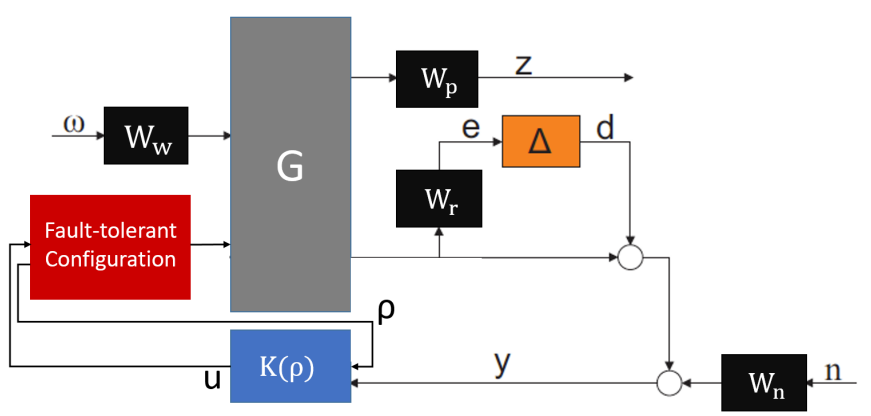

Fig. 2. Closed-loop interconnection structure

In the interconnection structure, $G$ is the quarter-car model defined in (3), $K$ is the designed LPV controller characterized with the scheduling variable $\rho$ responsible for control reconfiguration, $u$ defines the control input, $y$ represents the measured output, $n$ expresses the measurement noise, $z$ represents the performance outputs, $w$ stands for the road disturbance, while the fault-tolerant configuration block is responsible for reconfiguration, which is described in Section III.

The weighting functions $W_{n}$ and $W_{w}$ aims to represent sensor noise and road disturbances, while $W_{r}$ stands for the parameter uncertainties. Weighting function $W_{p}$ is to keep the suspension deflection $\left(W_{p d}\right)$, the sprung mass acceleration $\left(W_{p a}\right)$ and tire deflection $\left(W_{p t}\right)$ small over the required frequency range. Note, that $W_{p a}$ stands for passenger comfort, $W_{p d}$ and $W_{p t}$ stands for stability and dynamic tire load. The another weighting function, which is responsible for the fault configuration will be described in the next section. The weighting functions are selected in a second-order proportional form as listed in below, where $\alpha$ and $T$ are design parameters. The result of the presented design is a reconfigurable LPV controller.

$$
W_{p_{a}, p_{d}, p_{t}}=\frac{\alpha_{1,2,3} s+1}{T_{1,2,3} s+1}
$$

The LPV performance problem is to choose a parametervarying controller, which guarantees quadratic stability for the closed-loop system while the induced $\mathcal{L}_{2}$ norm from the disturbance $\omega$ to the performances $z$ is smaller than the value $\tau$, as described in [12], [13]. Hence, the minimization task is given as:

$$
\inf _{K} \sup _{\varrho \in \mathcal{F}_{\mathcal{P}}\|w\|_{2} \neq 0, w \in \mathcal{L}_{2}} \sup _{\|w\|_{2}} \frac{\|z\|_{2}}{\| w .}
$$

The solution of an LPV problem is governed by the set of infinite dimensional LMIs being satisfied for all $\rho \in \mathcal{F}_{\mathcal{P}}$, thus it is a convex problem. In practice, this problem is set up by gridding the parameter space and solving the set of LMIs that hold on the subset of $\mathcal{F}_{\mathcal{P}}$, see [14].

The MR damper has limitations on the control input force, thus a semi-optimal solution is given as follows:

$$
F_{M R}= \begin{cases}F_{o p t}, & \text { if } \quad \dot{q}_{1}\left(\dot{q}_{1}-\dot{q}_{2}\right)>0 \\ F_{\text {pas }}, & \text { if } \dot{q}_{1}\left(\dot{q}_{1}-\dot{q}_{2}\right)<0\end{cases}
$$

where $F_{\text {opt }}$ is optimal force, $F_{\text {pas }}$ is passive suspension force, $\dot{q}_{1}$ is sprung mass velocity and $\dot{q}_{1}-\dot{q}_{2}$ is deflection velocity.

\section{FAULT-TOLERANT CONTROL CONFIGURATION METHOD}

This section represents a fault-tolerant control reconfiguration method, which calculates the feasible damper force for the healthy dampers to compensate for the force loss of the faulty damper in order to guarantee the stability of the vehicle and driving comfort. The model of oil leakage fault, which induces a lack of force in one of the semi-active dampers is written as follows:

$$
F_{m r_{i, j}}^{\circ}=\tau F_{m r_{i, j}}=F_{m r_{i, j}}-F_{\xi_{i, j}}
$$

Here, $F_{m r_{i, j}}^{\circ}$ is the faulty damper force, $\tau \in(0,1]$ is the degree of oil leakage, $F_{\xi_{i, j}}$ is lost force due to oil leakage fault and $i$ and $j$ express the damper location, where $i \in$ $\{$ front, rear $\}, j \in\{$ left, right $\}$.

The fault-tolerant damper force(compensated) that is needed to apply to other dampers is given as:

$$
F_{F T_{i, j}}=F_{m r_{i, j}}-F_{C_{i, j}}
$$

where, $F_{C_{i, j}}$ is stabilization force, which is applied in order to calculate the fault-tolerant damper force and it is calculated as follows:

$$
F_{C_{i, j}}=\left[\eta(\rho) F_{m r_{i, j}}\right]
$$

Here, $\eta$ is the fault reconfiguration coefficient that is a function of the weighting function $W_{\text {conf }}$, which is under the fault-tolerant configuration block and is modified with scheduling variable $\rho$. This weighting function is selected in a second-order proportional form.

$$
W_{\text {conf }}=\rho \frac{\alpha_{4} s+1}{T_{4} s+1}
$$

The final equation for the fault-tolerant damper force is written as below by arranging Equation (8) and (9):

$$
F_{F T_{i, j}}=F_{m r_{i, j}}-\left[\eta(\rho) F_{m r_{i, j}}\right]
$$


The selection of the scheduling variable $\rho \in[0.01,0.99]$ is based on the generated multiple stochastic simulations in TruckSim with different road conditions and vehicle velocities. For example, the result of one of these simulations (rear-right damper) with sine-sweep road distortion and 70 $\mathrm{km} / \mathrm{h}$ velocity is shown in Figure 3. Here, different scheduling variables are applied to modify $\eta$ and correspondingly damper force. As it is shown in the figure, the damping force decreases by reducing the scheduling variable $\rho$. In case a fault occurs, the scheduling variable is needed to be chosen smaller in order to reduce the damping force.Damper force changes subjected the different scheduling variables are defined as scheduling variable change $(\Delta \rho)$. In order to have the same level damping force with faulty damper force, $\Delta \rho$ is selected depending on the degree of oil leakage. In this study, the degree of oil leakage is assumed as $\tau=0.93$. Thus, the corresponding change in the scheduling variable is $\Delta \rho=-0.255$. The scheduling variable is defined as $\rho=0.745$ in the fault-free case. According to our approach, the change in scheduling variable in the healthy damper is calculated as a difference, thus the scheduling variable is selected as $\rho=0.49$ in the faulty case.

Table II shows the necessary change in the scheduling variable in different fault conditions of the degree of oil leakage. This scheduling variable selection logic is based on multiple TruckSim simulations with different velocity and road conditions.

TABLE II

SCHEDULING VARIABLE SELECTION

\begin{tabular}{|l|l|}
\hline Fault condition & Change in scheduling variable $(\Delta \rho)$ \\
\hline \hline $1>\tau>0.95$ & -0.127 \\
\hline $0.95>\tau>0.85$ & -0.255 \\
\hline $0.85>\tau>0.65$ & -0.382 \\
\hline $0.65>\tau>0.55$ & -0.5 \\
\hline$\tau<0.55$ & -0.745 \\
\hline
\end{tabular}

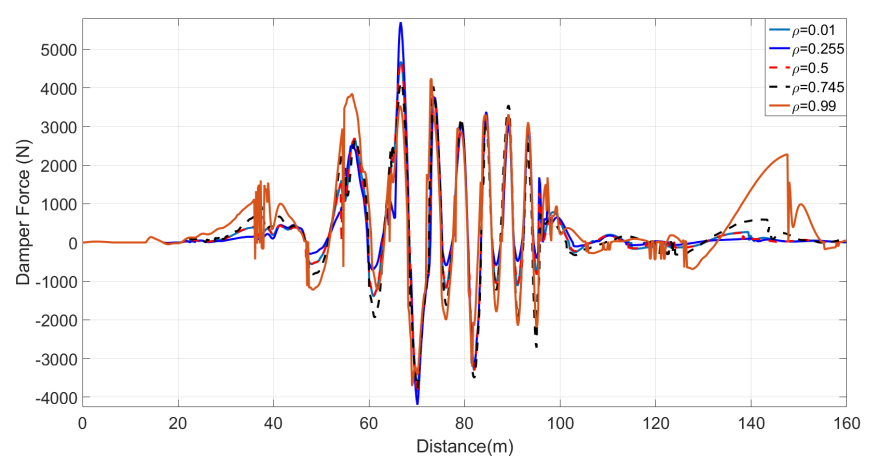

Fig. 3. Damper force changes

As it is shown in Figure 4, an LPV-based semi-active controller and fault reconfiguration block is given for each corner of the vehicle. The calculated $\rho$ by the fault reconfiguration is forwarded to the semi-active controller, while in the first time step, $\rho$ is selected as $0.745 . F_{D_{i, j}}$ is the damper force that is forwarded to the vehicle damper, where it is selected with Equation (12). Here, $\vartheta$ is the fault monitor, where $\vartheta=0$ expresses fault-free, $\vartheta=1$ expresses faulty case. If there is a fault in the damper, calculated $F_{F T_{i, j}}$ is forwarded to the system otherwise, the damper force $F_{m r_{i, j}}$, which is calculated by the LPV controller is forwarded.

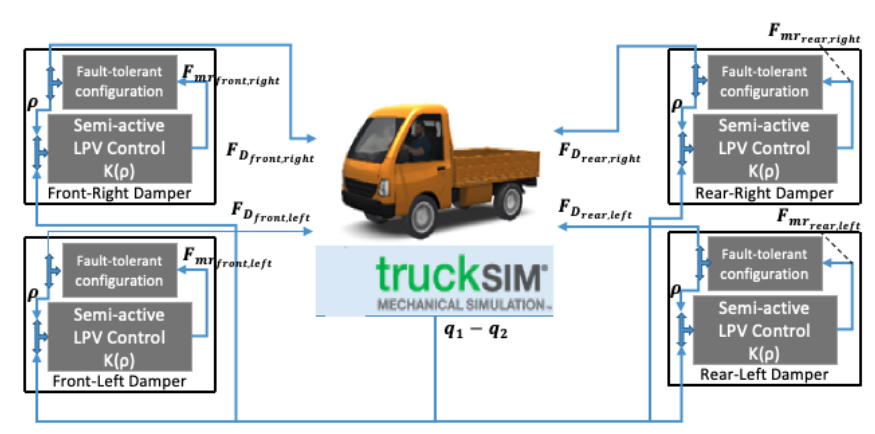

Fig. 4. Integration of the fault configuration

$$
F_{D_{i, j}}= \begin{cases}F_{F T_{i, j}}, & \text { if } \vartheta=1 \\ F_{m r_{i, j}}, & \text { if } \vartheta=0\end{cases}
$$

Note, that fault detection and estimation are not considered in this study, since the focus of this paper is fault-tolerant reconfiguration. Hence, it is assumed that fault can be detected by fault detection methods, see [2]. This method monitors the suspension transmissibility, thus magnitude ratio between the sprung and unsprung mass accelerations allows to detect a fault in a damper. The author proposed two approaches in order to detect a fault in the MR damper. The first one is force sensor-based and computes the damping ratio online. It utilizes the force from the damper model as a virtual sensor and computes the instantaneous damping ratio. The second one is accelerometers sensor-based and computes the maximum value of vertical acceleration measurements in a regressive sampling horizon. This approach defines the vertical coordinate of the pseudo-bode in case of magnitude of the transmissibility is based only on the acceleration measurements. In this study, it is assumed that the fault is detected by this second approach, while the TruckSim allows measuring the accelerations with an accelerometer sensor and it is easy to apply in this study.

A brief symbolic simulation has been performed in the Simulink with a $0.05 \mathrm{~m}$ bump in order to show the relation between $F_{m r_{i, j}}^{\circ}$ and $F_{m r_{i, j}}$. The degree of oil leakage $\tau$ is assumed as 0.7 , where lost force $F_{\xi_{\text {rear,left }}}$ is $30 \%$ of the damper force. The result shows that, $\left|F_{m r_{\text {rear,left }} \mid}^{\circ}\right|<$ $\left|F_{m r_{\text {rear,left }}}\right|$ in each point (left side in Figure 5), while rootmean-square(RMS) value of $F_{m r_{i, j}}^{\circ}$ is decreased in the fault scenario due to $30 \%$ lost force $F_{\xi_{\text {rear }, \text { eft }}}$ (right side in the Figure 5). 


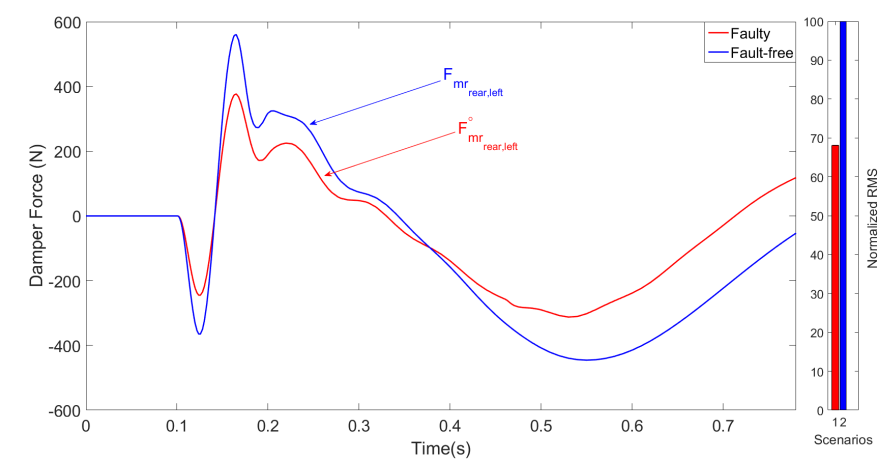

Fig. 5. MR damper forces

\section{Simulation Results}

A compact utility truck has been chosen in TruckSim with fully independent suspension, having the physical parameters detailed in Table III for the simulation of the proposed faulttolerant semi-active suspension system. Figure 6 shows char-

TABLE III

PARAMETERS OF THE COMPACT UTILITY TRUCK

\begin{tabular}{|l|l|l|}
\hline Parameter & Value & Unit \\
\hline \hline Truck mass $\left(m_{t}\right)$ & 760 & $\mathrm{~kg}$ \\
Payload mass $\left(m_{p}\right)$ & 500 & $\mathrm{~kg}$ \\
Distance from C.G to front axle $\left(l_{1}\right)$ & 0.55 & $\mathrm{~m}$ \\
Distance from C.G to rear axle $\left(l_{2}\right)$ & 1.375 & $\mathrm{~m}$ \\
Track width $(b)$ & 1.26 & $\mathrm{~m}$ \\
Height of COG $\left(h_{C O G}\right)$ & 0.813 & $\mathrm{~m}$ \\
Maximal suspension deflection $\left(d_{\max }\right)$ & 70 & $\mathrm{~mm}$ \\
Vehicle velocity $(v)$ & 70 & $\mathrm{~km} / \mathrm{h}$ \\
\hline
\end{tabular}

acteristics of the selected road distortion. This longitudinal sinusoidal road irregularity with growing frequency gives extreme stress on the suspension system of the simulated vehicle, while it is a quite realistic distortion to prove the effectiveness of the introduced method. This kind of road irregularity is typical at bus stops, where the frequent braking of heavy road vehicles roll up the asphalt.

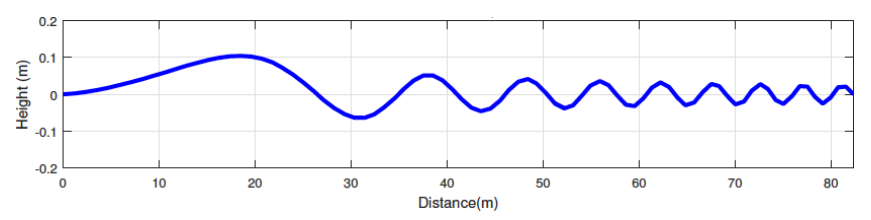

Fig. 6. Road distortion

In order to demonstrate the effectiveness of the proposed method, three different simulations have been performed and their simulation results are compared. The first scenario is with the utility truck having conventional semiactive suspension without any suspension-related fault, the second one with one faulty damper (rear-left) without faulttolerant properties, while the last one is the fault-tolerant (compensated) method.
Faulty scenario is described as $7 \%$ of oil leakage $(\tau=$ 0.93), which decreases the damper force around $6 \%$ in the rear-left damper. Both fault-free and faulty damper forces of rear-left damper is shown in Figure 7.

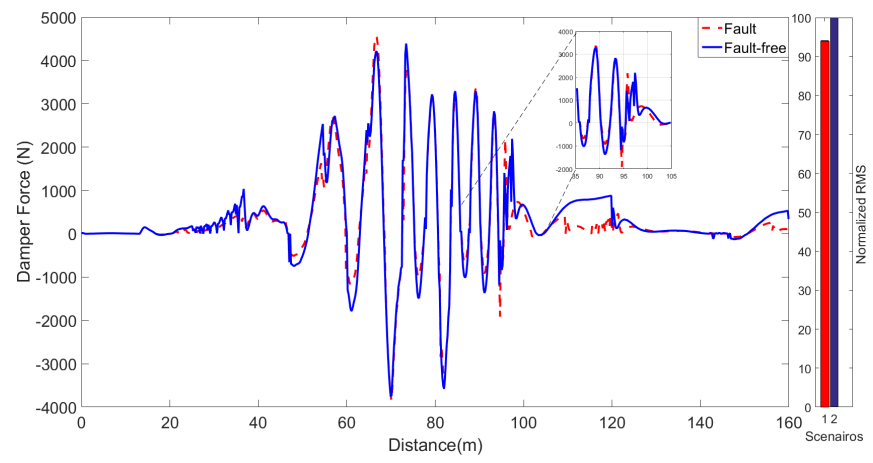

Fig. 7. Comparison of damper forces

As it is designed in the fault-tolerant strategy, damping forces of the healthy dampers also have been decreased in order to guarantee stability and comfort of the vehicle. This compensated and fault-free damping forces for the healthy damper front-rear is shown in Figure 8.

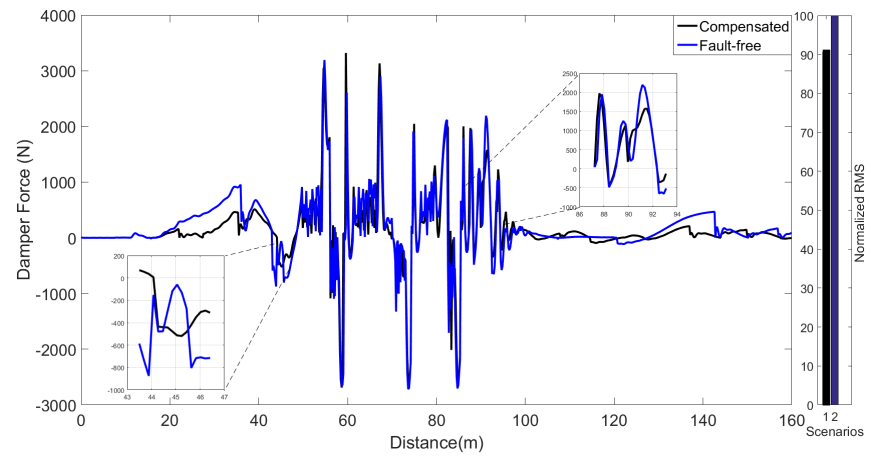

Fig. 8. Healthy damper forces

It is well demonstrated in the simulation, that even for this relatively small performance degradation in one damper, the overall comfort and stability of the vehicle can be improved significantly.

As it is shown in Figure 9, by using the RMS value of the roll angle of the vehicle as a comfort performance index, compensated with respect to the faulty scenario, the introduced fault-tolerant control strategy improved the driving comfort by $25 \%$. The RMS value of the roll angle in the faulty scenario is 0.0084 , while this value is 0.0063 in the fault-tolerant case. Hence, comfort and roll stability of the vehicle increased significantly with the proposed faulttolerant method, even with the relatively small oil leakage level.

Note, that other stability related performances of the simulated vehicle also improved. For example, as depicted in Figure 10, the deflection of the healthy front-right suspension also reduced with the proposed fault-tolerant method. While 


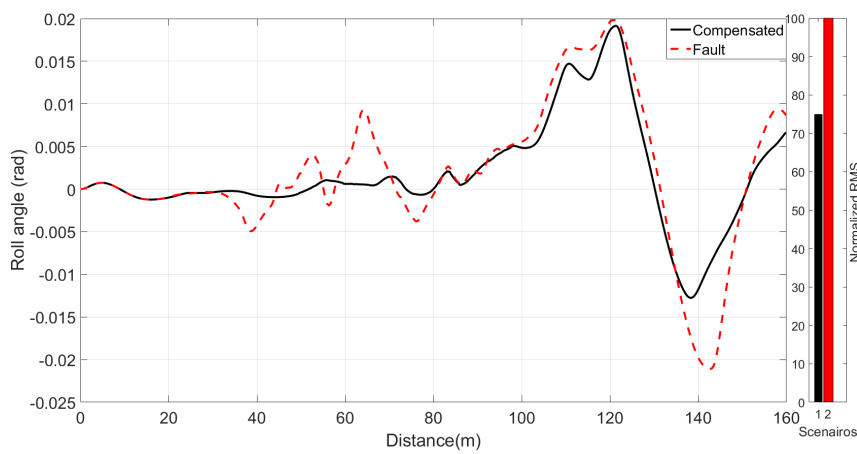

Fig. 9. Roll angle

the RMS value of the suspension deflection in the noncompensated faulty scenario is 0.03 , with the proposed the fault-tolerant controller it reduced to 0.0275 .

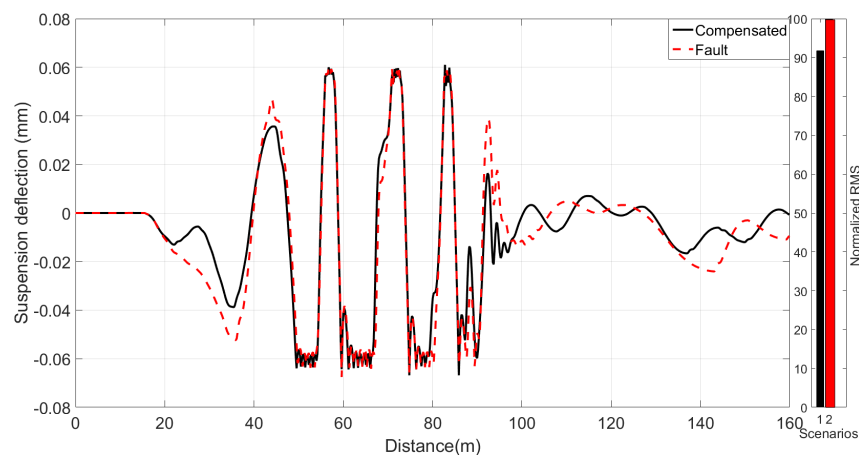

Fig. 10. Suspension deflection

Moreover, the road holding of the simulated vehicle also improved, showing reduced values in tire deformation. As depicted in Figure 11, tire deformation of the front-right suspension reduced slightly, with an RMS value of 0.042 for the nominal case, and 0.0389 value for the proposed faulttolerant case.

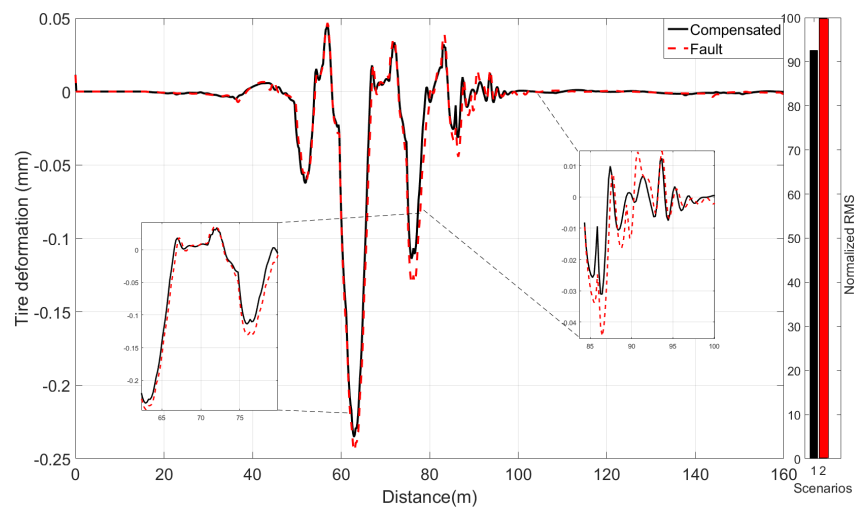

Fig. 11. Tire deformation

\section{CONCLUSION}

The design of semi-active suspension control with faulttolerant control reconfiguration through LPV control method has been proposed in this study. The main objective of this paper is to design a semi-active controller and integrate a fault-tolerant reconfiguration strategy in order to compensate for the damper fault effects. The fault-tolerant reconfiguration strategy calculates the feasible damper force for the healthy dampers in case one of the dampers suffers a fault. Multiple simulations have been performed in order to demonstrate the operation of the proposed fault-tolerant control reconfiguration method in the TruckSim environment. The results of the simulation proved that the designed semiactive controller with the introduced fault-tolerant strategy improved the stability and comfort-related performance.

\section{REFERENCES}

[1] J. C. Dixon, The shock absorber handbook. John Wiley \& Sons, 2008.

[2] J. de Jesus Lozoya-Santos, J. C. Tudón-Martinez, R. MoralesMenendez, R. Ramirez-Mendoza, and L. E. Garza-Castanon, "A fault detection method for an automotive magneto-rheological damper," IFAC Proceedings Volumes, vol. 45, no. 20, pp. 1209 - 1214, 2012, 8th IFAC Symposium on Fault Detection, Supervision and Safety of Technical Processes.

[3] M. Fleps-Dezasse, F. Svaricek, and J. Brembeck, "Damper faulttolerant linear parameter-varying semi-active suspension control," IFAC-PapersOnLine, vol. 50, no. 1, pp. 8592 - 8599, 2017.

[4] T.-P. Pham, "Lpv observer and fault-tolerant control of vehicle dynamics: application to an automotive semi-active suspension system," Ph.D. dissertation, Université Grenoble Alpes [2020-....], 2020.

[5] M. M. Morato, O. Sename, and L. Dugard, "Lpv-mpc fault tolerant control of automotive suspension dampers," IFAC-PapersOnLine, vol. 51, no. 26, pp. 31-36, 2018.

[6] X. Du, G. Han, M. Yu, Y. Peng, X. Xu, and J. Fu, "Fault detection and fault tolerant control of vehicle semi-active suspension system with magneto-rheological damper," Smart Materials and Structures, vol. 30 , no. 1 , p. 014004,2020

[7] M. M. Morato, O. Sename, and L. Dugard, "Design and analysis of several state-feedback fault-tolerant control strategies for semi-active suspensions," IFAC-PapersOnLine, vol. 52, no. 17, pp. 48-53, 2019.

[8] S. A. Rueda Villanoba and C. Borrás Pinilla, "Neural network based fault tolerant control for a semi-active suspension," in ASME International Mechanical Engineering Congress and Exposition, vol. 59414. American Society of Mechanical Engineers, 2019, p. V004T05A089.

[9] H. Basargan, A. Mihály, P. Gáspár, and O. Sename, "Integrated multicriteria velocity and semi-active suspension control based on lookahead road information," in 2020 28th Mediterranean Conference on Control and Automation (MED), 2020, pp. 25-30.

[10] H. Basargan, A. Mihály, P. Gáspár, and O. Sename, "Adaptive semiactive suspension and cruise control through lpv technique," Applied Sciences, vol. 11, no. 1, p. 290, 2021.

[11] H. Basargan, A. Mihály, P. Gáspár, and O. Sename, "Adaptive semiactive suspension control considering look-ahead road information and irregularities," in VSDIA 2020 - 17th Mini Conference on Vehicle System Dynamics, Identification and Anomalies, 2020.

[12] J. Bokor and G. Balas, "Linear parameter varying systems: A geometric theory and applications," 16th IFAC World Congress, Prague, 2005.

[13] A. Packard and G. Balas, "Theory and application of linear parameter varying control techniques," American Control Conference, Workshop I, Albuquerque, New Mexico, 1997.

[14] F. Wu, X. H. Yang, A. Packard, and G. Becker, "Induced $l^{2}$-norm control for LPV systems with bounded parameter variation rates," International Journal of Nonlinear and Robust Control, vol. 6, pp. 983-998, 1996. 